NASA/TP-2009-215779

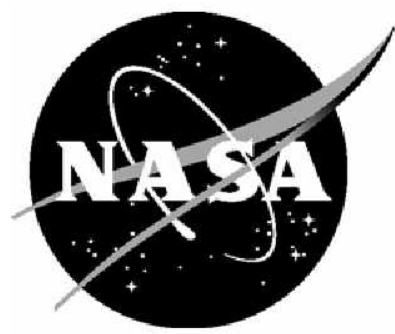

\title{
Validity of the Aluminum Equivalent Approximation in Space Radiation Shielding
}

Francis F. Badavi

Christopher Newport University, Newport News, Virginia

Daniel O. Adams

University of Utah, Salt Lake City, Utah

John W. Wilson

NASA Langley Research Center, Hampton, Virginia 


\section{NASA STI Program ... in Profile}

Since its founding, NASA has been dedicated to the advancement of aeronautics and space science. The NASA scientific and technical information (STI) program plays a key part in helping NASA maintain this important role.

The NASA STI program operates under the auspices of the Agency Chief Information Officer. It collects, organizes, provides for archiving, and disseminates NASA's STI. The NASA STI program provides access to the NASA Aeronautics and Space Database and its public interface, the NASA Technical Report Server, thus providing one of the largest collections of aeronautical and space science STI in the world. Results are published in both non-NASA channels and by NASA in the NASA STI Report Series, which includes the following report types:

- TECHNICAL PUBLICATION. Reports of completed research or a major significant phase of research that present the results of NASA programs and include extensive data or theoretical analysis. Includes compilations of significant scientific and technical data and information deemed to be of continuing reference value. NASA counterpart of peerreviewed formal professional papers, but having less stringent limitations on manuscript length and extent of graphic presentations.

- TECHNICAL MEMORANDUM. Scientific and technical findings that are preliminary or of specialized interest, e.g., quick release reports, working papers, and bibliographies that contain minimal annotation. Does not contain extensive analysis.

- CONTRACTOR REPORT. Scientific and technical findings by NASA-sponsored contractors and grantees.
- CONFERENCE PUBLICATION. Collected papers from scientific and technical conferences, symposia, seminars, or other meetings sponsored or co-sponsored by NASA.

- SPECIAL PUBLICATION. Scientific, technical, or historical information from NASA programs, projects, and missions, often concerned with subjects having substantial public interest.

- TECHNICAL TRANSLATION. Englishlanguage translations of foreign scientific and technical material pertinent to NASA's mission.

Specialized services also include creating custom thesauri, building customized databases, and organizing and publishing research results.

For more information about the NASA STI program, see the following:

- Access the NASA STI program home page at http://www.sti.nasa.gov

- E-mail your question via the Internet to help@sti.nasa.gov

- Fax your question to the NASA STI Help Desk at $443-757-5803$

- Phone the NASA STI Help Desk at 443-757-5802

- Write to:

NASA STI Help Desk NASA Center for AeroSpace Information 7115 Standard Drive Hanover, MD 21076-1320 
NASA/TP-2009-215779

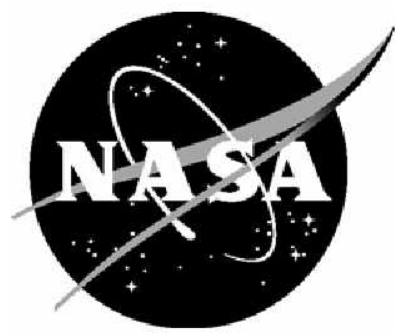

\section{Validity of the Aluminum Equivalent Approximation in Space Radiation Shielding}

Francis F. Badavi

Christopher Newport University, Newport News, Virginia

Daniel O. Adams

University of Utah, Salt Lake City, Utah

John W. Wilson

NASA Langley Research Center, Hampton, Virginia

National Aeronautics and

Space Administration

Langley Research Center

Hampton, Virginia 23681-2199

July 2009 
Available from:

NASA Center for AeroSpace Information 7115 Standard Drive

Hanover, MD 21076-1320

443-757-5802 


\section{Nomenclature}

\begin{tabular}{|c|c|}
\hline ACE & $=$ Advanced Composition Explorer \\
\hline $\mathrm{D}$ & $=$ Dose $(\mathrm{cGy})$ \\
\hline $\mathrm{E}$ & $=$ Kinetic energy $(\mathrm{MeV})$ \\
\hline GCR & $=$ Galactic Cosmic Ray \\
\hline $\mathrm{GeV}$ & $=$ Giga electron Volt \\
\hline $\mathrm{H}$ & $=$ Hydrogen \\
\hline HZETRN & $=$ High charge $(Z)$ and Energy TRaNsport code \\
\hline ICES & $=$ International Conference on Environmental Systems \\
\hline ISS & $=$ International Space Station \\
\hline LaRC & $=$ Langley Research Center \\
\hline LEO & $=$ Low Earth Orbit \\
\hline LIS & $=$ Local Interplanetary Spectrum \\
\hline $\mathrm{MC}$ & $=$ Monte Carlo \\
\hline $\mathrm{MeV}$ & $=$ Mega electron Volt \\
\hline $\mathrm{Ni}$ & $=$ Nickel \\
\hline NIST & $=$ National Institute of Standards and Technology \\
\hline PE & $=$ Polyethylene $\left(\mathrm{CH}_{2}\right)$ \\
\hline PET & $=$ Polyethylene Terephthalate $\left(\mathrm{C}_{10} \mathrm{H}_{8} \mathrm{O}_{4}\right)$ \\
\hline PP & $=$ Polypropylene \\
\hline RBE & $=$ Relative Biological Effectiveness \\
\hline $\mathrm{R}(50)$ & $=$ Range at $50 \mathrm{MeV}$ protons $\left(\mathrm{g} / \mathrm{cm}^{2}\right)$ \\
\hline $\mathrm{S}$ & $=$ Stopping power $\left(\mathrm{MeV} / \mathrm{g} / \mathrm{cm}^{2}\right)$ \\
\hline SAE & $=$ Society of Automotive Engineers \\
\hline SAMPE & $=$ Society for the Advancement of Material and Process Engineering \\
\hline SPE & $=$ Solar particle event \\
\hline Z & $=$ Particle charge number \\
\hline$\varphi$ & $=$ Differential GCR flux $\left[\# /\left(\mathrm{MeV}-\mathrm{cm}^{2}\right.\right.$-day $\left.)\right]$ \\
\hline
\end{tabular}




\section{Contents}

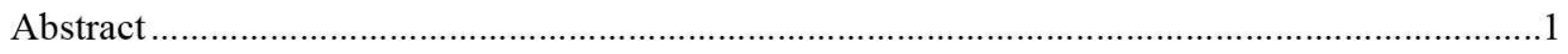

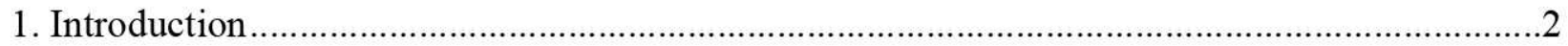

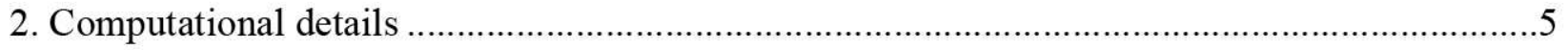

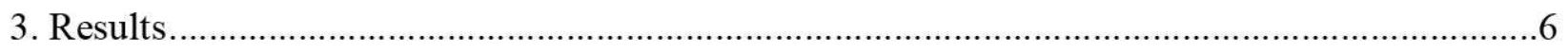

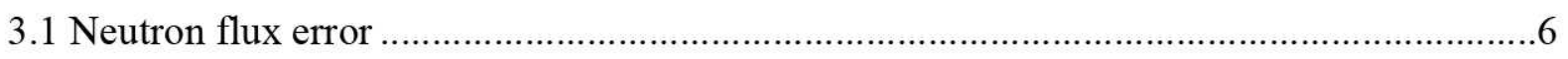

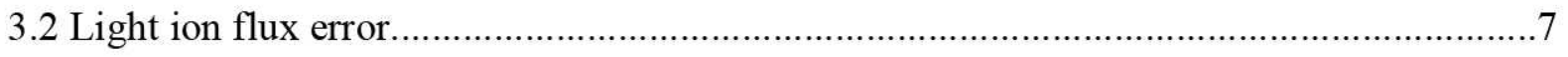

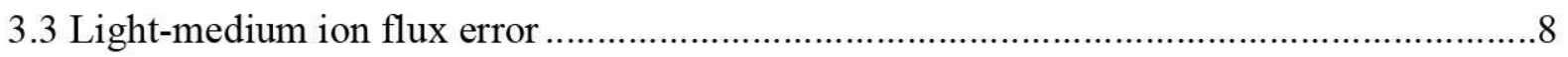

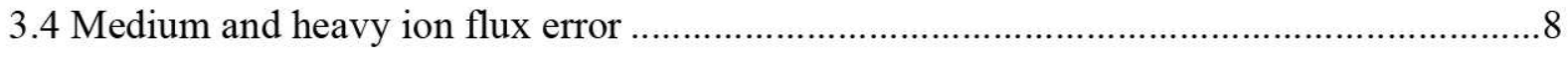

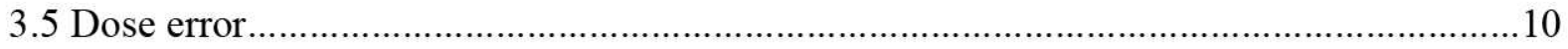

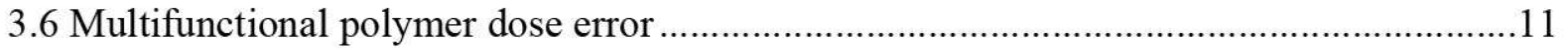

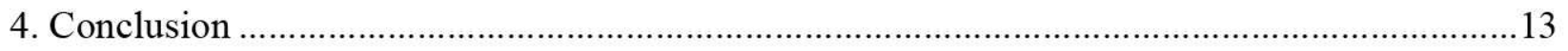

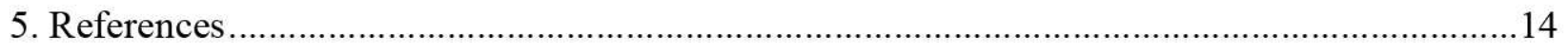




\section{Figures}

1. Absorbed dose in a water shield for a $592 \mathrm{MeV}$ proton beam................................................. 3

2. Percent dose contribution due to nuclear reactions for a proton beam of varying energy impinging on a water column....

3. Percent relative error for neutron flux for the 1977 and 2001 GCR environments (PE vs. aluminum equivalent $\mathrm{PE}$ )

4. Percent relative error for the combined light ion (proton, deuteron, triton, helion and helium) flux for the 1977 and 2001 GCR environments (PE vs. aluminum equivalent PE).....

5. Percent relative error for the combined charges 3 through 10 ion group flux for the 1977 and 2001 GCR environments (PE vs. aluminum equivalent PE).

6. Percent relative error for the combined charges 11 through 20 ion group flux for the 1977 and 2001 GCR environments (PE vs. aluminum equivalent PE)

7. Percent relative error for the combined charges 21 through 28 ion group flux for the 1977 and 2001 GCR environments (PE vs. aluminum equivalent PE).

8. Percent relative error for the absorbed dose for the 1977 and 2001 GCR environments (PE vs. aluminum equivalent $\mathrm{PE}$ ).

9. Percent relative error for the absorbed dose for the 1977 and 2001 GCR environments (multifunctional polymer vs. aluminum equivalent multifunction polymer) 


\section{Tables}

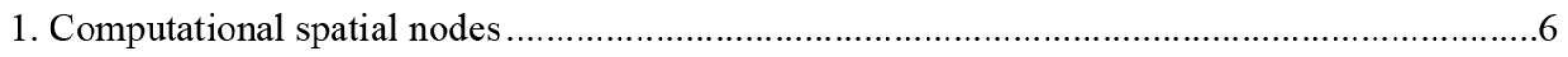

2. Properties of the target multifunctional polymers investigated ...............................................11

3. $50 \mathrm{MeV}$ proton range for the target multifunctional polymers investigated …......................12 


\begin{abstract}
The origin of the aluminum equivalent shield approximation in space radiation analysis can be traced back to its roots in the early years of the NASA space programs (Mercury, Gemini and Apollo) wherein the primary radiobiological concern was the intense sources of ionizing radiation causing short term effects which was thought to jeopardize the safety of the crew and hence the mission. Herein, it is shown that the aluminum equivalent shield approximation, although reasonably well suited for that time period and to the application for which it was developed, is of questionable usefulness to the radiobiological concerns of routine space operations of the $21^{\text {st }}$ century which will include long stays onboard the International Space Station (ISS) and perhaps the moon. This is especially true for a risk based protection system, as appears imminent for deep space exploration where the long-term effects of Galactic Cosmic Ray (GCR) exposure is of primary concern. The present analysis demonstrates that sufficiently large errors in the interior particle environment of a spacecraft result from the use of the aluminum equivalent approximation, and such approximations should be avoided in future astronaut risk estimates. In this study, the aluminum equivalent approximation is evaluated as a means for estimating the particle environment within a spacecraft structure induced by the $G C R$ radiation field. For comparison, the two extremes of the GCR environment, the 1977 solar minimum and the 2001 solar maximum, are considered. These environments are coupled to the Langley Research Center (LaRC) deterministic ionized particle transport code High charge (Z) and Energy TRaNsport (HZETRN), which propagates the GCR spectra for elements with charges $(Z)$ in the range $1 \leq Z \leq 28(\mathrm{H}-\mathrm{Ni})$ and secondary neutrons through selected target materials. The coupling of the GCR extremes to HZETRN allows for the examination of the induced environment within the interior of an idealized spacecraft as approximated by a spherical shell shield, and the effects of the aluminum equivalent approximation for a good polymeric shield material such as generic polyethylene (PE). The shield thickness is represented by a $25 \mathrm{~g} / \mathrm{cm}^{2}$ spherical shell. Although one could imagine the progression to greater thickness, the current range will be sufficient to evaluate the qualitative usefulness of the aluminum equivalent approximation. Upon establishing the inaccuracies of the aluminum equivalent approximation through numerical simulations of the GCR radiation field attenuation for $P E$ and aluminum equivalent $P E$ spherical shells, we further present results for a limited set of commercially available, hydrogen rich, multifunctional polymeric constituents to assess the effect of the aluminum equivalent approximation on their radiation attenuation response as compared to the generic $P E$.
\end{abstract}




\section{Introduction}

The space radiation concerns of the early years of the US space programs (Mercury, Gemini and Apollo) were for the more intense sources of ionizing radiation, requiring protection to avoid radiation sickness which could impact mission safety or even cause death during the mission (ref. 1). The Relative Biological Effectiveness (RBE) for such effects was assumed to be near unity, so that the energy absorbed per unit mass of tissue (i.e. dose) was the indicator of health prognosis, which led to considerable simplification in dosimetry analysis in which tissue equivalent ion chambers played a dominant role. The primary environments of concern were for the geomagnetically trapped radiation belts (i.e. protons and electrons) and high flux Solar Particle Events (SPE), in which protons are the largest constituents and contributions of secondary radiations to the dose from both trapped and SPE environments are limited. For example, a $100 \mathrm{MeV}$ proton will have a few percent probability of a nuclear reaction in coming to rest by a cascade of atomic interactions. These considerations were carried out in the spacecraft shield design in which nuclear reactions were normally ignored in the design process (refs. 2, 3). For historical reasons, it is important to note that the exclusion of nuclear processes contribution to the dose to evaluate the secondary radiation field in even a simplified geometry was in part motivated by the very long computational time required by the available Apollo era statistical based Monte Carlo (MC) particle transport methodologies.

In the post-Apollo era, space operations became somewhat more routine. The increase in number of astronauts and the frequency of space visits to Low Earth Orbit (LEO) stations such as Skylab, Mir and the International Space Station (ISS) gradually required a reassessment of the astronaut protection practices with emphasis on deeper understanding of the potential long term genetic mutation and carcinogenic tumor development processes (ref. 4).

Generally, the RBE for such biological endpoints within the human body, where cancer based genetic mutations may initiate, can be large. This is especially true for the types of secondary radiation produced in the spacecraft materials and human tissues (refs. 5, 6), pointing to the fact that the older dosimetric methods based on tissue equivalent ion chambers (e.g. dose) are potentially inadequate. For example, for the absorbed dose in a water shield, figure 1 compares the analytic fit (nominal $600 \mathrm{MeV}$ protons), derived through the build up factor formalism (ref. 6), with experimental (592 MeV proton beam) dose measurements (ref. 7). The figure indicates that the formalism of build up which accounts for the nuclear contribution to the dose, correlates very well with the measurement of reference 7 . In the figure, the noticeable sharp rise in the absorbed dose toward the end of beam range is the Bragg peak. This peak occurs because the interaction cross section between the beam and the target increases as the beam energy decreases through atomic and nuclear collisions. The very sharp rise in the absorbed dose at the Bragg peak is often exploited in proton and heavy ion radiotherapy for the treatment of cancer. Also shown are the uncollided primaries, where effects of nuclear collisions are ignored. From the figure, it is obvious that the secondary particle contribution to the absorbed dose due to nuclear processes, especially at low depths, is important in radiation risk estimation for such particles and can't be ignored. 


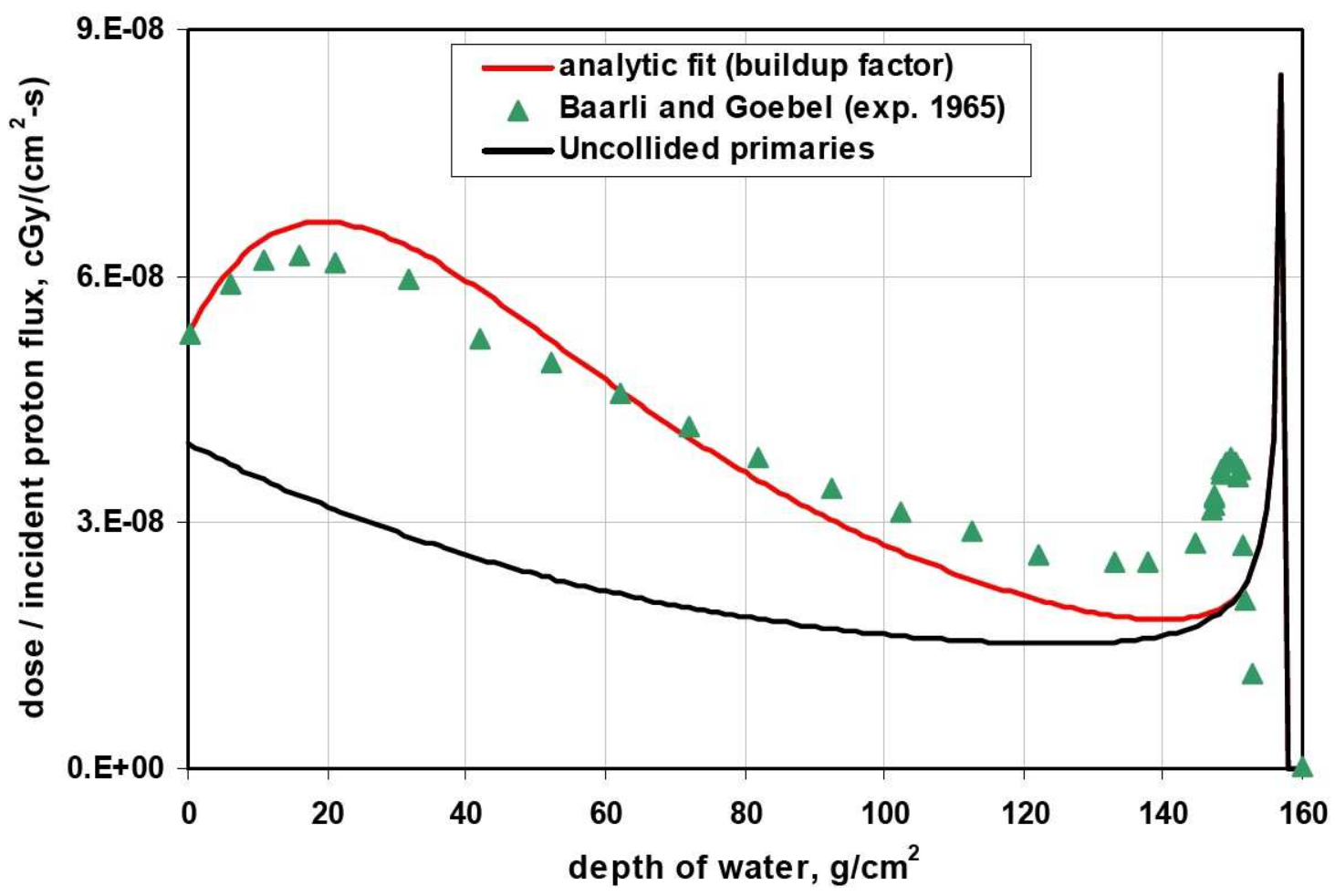

Figure 1. Absorbed dose in a water shield for a $592 \mathrm{MeV}$ proton beam.

Ignoring the nuclear processes, the atomic interactions are mainly related to the number of electrons per unit volume of material, with small material specific electron binding corrections. Consequently, from a practical design point of view, shield properties neglecting nuclear reactions can be scaled from one material to another with a fair degree of accuracy. In the field of space vehicle design, it was once customary to express all shield materials in terms of aluminum equivalent by scaling the effective shield thickness of each material type in terms of the range of a $50 \mathrm{MeV}$ proton as follows

$$
\mathrm{X}_{\mathrm{eq} \cdot \mathrm{Al}}=\left[\mathrm{R}_{\mathrm{Al}}(50) / \mathrm{R}_{\mathrm{m}}(50)\right] \cdot \mathrm{X}_{\mathrm{m}}
$$

where $\mathrm{R}_{\mathrm{Al}}(50)$ is the calculated range of a $50 \mathrm{MeV}$ proton in aluminum $\left(\sim 3 \mathrm{~g} / \mathrm{cm}^{2}\right)$ and $\mathrm{R}_{\mathrm{m}}(50)$ in $\mathrm{g} / \mathrm{cm}^{2}$ is the corresponding range in the specific shield material. The ratio in the brackets in equation 1 then scales the thickness of material $X_{m}$ in $g / \mathrm{cm}^{2}$ to an equivalent thickness of aluminum $X_{\text {eq.Al in }} \mathrm{g} / \mathrm{cm}^{2}$, which will have the same shielding effectiveness if nuclear reactions are negligible. It is worth noting that by expressing material range in $\mathrm{g} / \mathrm{cm}^{2}$ in equation 1 , the effect of material density in $\mathrm{g} / \mathrm{cm}^{3}$ is automatically incorporated in the range calculation.

The approximation of ignoring nuclear reactions works well for the estimation of absorbed dose from impinging protons below roughly $100 \mathrm{MeV}$, where the proton range is only a few $\mathrm{g} / \mathrm{cm}^{2}$, but begins to generate error for dose at higher energies in the Galactic Cosmic Ray (GCR) energy domain. To emphasize the consequence of excluding nuclear reactions in an absorbed dose calculation, we return to the $160 \mathrm{~g} / \mathrm{cm}^{2}$ water column measurement of reference 7 as was shown in figure 1 and compute the percent nuclear contribution to the absorbed dose for proton beams of $100 \sim 1000 \mathrm{MeV}$. This is shown in figure 2 where low energy protons have a 


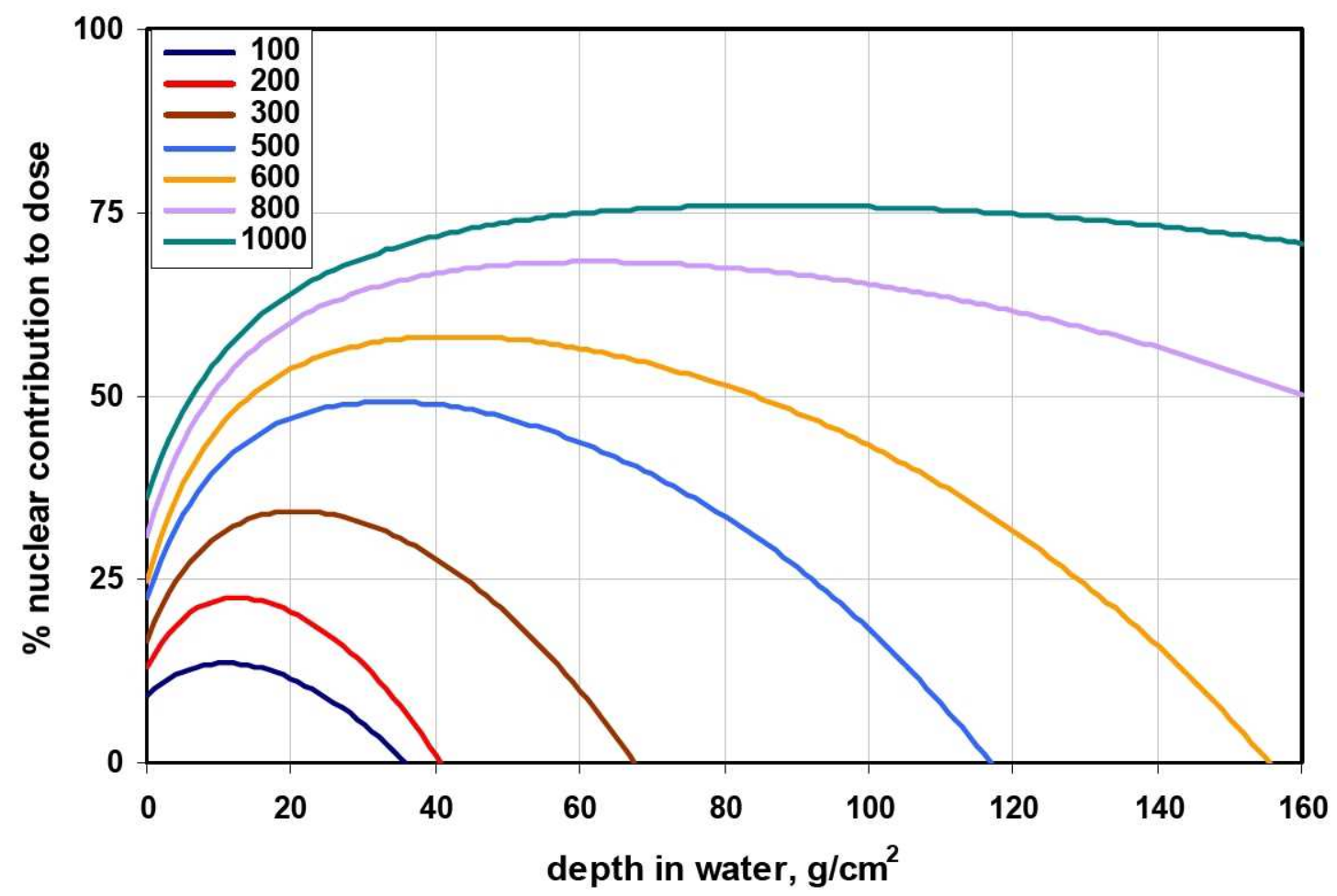

Figure 2. Percent dose contribution due to nuclear reactions for a proton beam of varying energy impinging on a water column.

relatively small nuclear contribution to dose and only above $500 \mathrm{MeV}$ or so begin to dominate the dose contribution due to nuclear reactions. This implies that for the energetic GCR ions in the $\mathrm{GeV}$ range, the approximation of equation 1 no longer holds. It is worth noting that the initial build up of the absorbed dose is due to secondary neutron production and noticeably for the absorbed dose, all nuclear interactions cease to exist near the Bragg peak.

In the free space environment, where the energies of proton and helium components of the GCR reach a few $\mathrm{GeV}$, the inclusion of nuclear processes in any mission planning dose estimation becomes more important due to the potential long duration of the mission. Even more importantly, in the GCR environment, the problem of estimating radiation health risks to the crew of the spacecraft is also strongly particle type dependent, and hence new methods for risk estimation must also include the establishment of an accurate particle environment (refs. 8, 9). Hence, for any space mission outside the protective geomagnetic field of the earth, great care in evaluation of the particle environment is the underpinning of astronaut health risk estimation (ref. 10).

In spite of the advances in computational procedures, due to simplicity of the aluminum equivalent approximation, many calculations are still being made using the equivalent approximation assumption (ref. 11). This assumption is mainly made out of convenience using readily available Monte Carlo (MC) databases generated many years ago. It is, therefore, useful to examine what limitations this assumption may have on risk estimate, which is the purpose of the present study. 


\section{Computational details}

In this study, the aluminum equivalent approximation is evaluated as a means for estimating the particle environment induced by the GCR radiation field within a spacecraft structure. For comparison, the two extremes of the GCR environment, the 1977 solar minimum and 2001 solar maximum, are considered. Prior work studied these extreme GCR environments in detail (ref. 12).

Models of free space GCR environment developed in the past two decades have provided the most realistic description of the interaction of incoming GCR from outside the heliosphere with solar activity. The model of O'Neill (ref. 13) is currently used as GCR input into the most recent version (2005) of the Langley Research Center (LaRC) deterministic ionized particle transport code High charge (Z) and Energy TRaNsport (HZETRN) (ref. 14). This GCR model is based on fitting the existing balloon and satellite measured energy spectra from $1954-1992$ and more recent measurements from the Advanced Composition Explorer (ACE) satellite from 1997 - 2002 to the stationary Fokker-Planck equation to solve the diffusion, convection, and energy loss boundary value problem and obtain an estimate of the appropriate diffusion coefficient. In addition, correlation of the diffusion coefficient to the Climax neutron monitor data which exhibits an odd-even cycle with a 22 year period, enables the estimation of the diffusion coefficient at times that direct observational data are not available. The latest implementation of this GCR model (2004) accurately accounts for the solar modulation of hydrogen through nickel $(\mathrm{H}-\mathrm{Ni}$ ) by propagating the Local Interplanetary Spectrum (LIS) of each element through the heliosphere. The model provides a single value of the deceleration parameter $\varphi(t)$ describing the level of solar cycle modulation and determines the GCR differential energy spectrum for elements $1 \leq Z \leq 28$ at any given radial distance from the sun.

The coupling of the GCR extreme environments to HZETRN allows for the examination of the induced environment within a spherical shell shield and the effects of the aluminum equivalent approximation for a good polymeric shield material such as generic polyethylene (PE). For numerical simulation, the shield thickness is restricted to $25 \mathrm{~g} / \mathrm{cm}^{2}$. Although one could imagine the progression to greater thickness, the current range will be sufficient to evaluate the qualitative usefulness of the aluminum equivalent approximation.

Upon establishing the inaccuracies of aluminum equivalent approximation through numerical comparisons of the GCR radiation field attenuation through PE and aluminum equivalent PE spherical shells, we further present results for a limited set of hydrogen rich polymeric constituents such as PE foam core, Spectra fiber composite facesheet, epoxy resin block and polyurethane carbon facesheet to assess the effect of the approximation in their radiation attenuation response as compared to generic PE. These off the shelf, commercially available, multifunctional polymers have promising physical and chemical characteristics as potential candidates in space applications. Through experimental testing and numerical simulation, prior reports have discussed the structural, thermal and radiation properties of these multifunctional polymers in great detail (refs. 15, 16). 


\section{Results}

The transport of the 1977 and 2001 GCR spectra in PE and aluminum equivalent PE spherical shell shields was evaluated and percent relative error of particle spectra in PE to that of aluminum equivalent $P E$ at the same equivalent thickness for $Z=0$, sum of $1 \leq Z \leq 2$, sum of $3 \leq$ $Z \leq 10$, sum of $11 \leq Z \leq 20$ and sum of $21 \leq Z \leq 28$ were evaluated. These charge dependent relative errors in flux provide an estimate of the limitation of the aluminum equivalent approximation for different charge groups in PE. In addition to charge group relative error computation, the percent relative error for dose was calculated, as this quantity represents the charge and energy integrated limitation of the equivalent approximation. Table 1 represents the computational spatial grid for $\mathrm{PE}$ and aluminum equivalent $\mathrm{PE}$ as described by equation 1 . In generating table 1 , values of $\mathrm{R}_{\mathrm{al}}(50)=2.93 \mathrm{~g} / \mathrm{cm}^{2}$ and $\mathrm{R}_{\mathrm{PE}}(50)=2.07 \mathrm{~g} / \mathrm{cm}^{2}$ as calculated by HZETRN, were used. This grid was used to propagate ions for both GCR extremes.

\begin{tabular}{|c|c|}
\hline $\mathbf{P E}\left(\mathbf{g} / \mathbf{c m}^{\mathbf{2}}\right)$ & Al-eq. $\mathbf{P E}\left(\mathbf{g} / \mathbf{c m}^{\mathbf{2}}\right)$ \\
\hline 0 & 0 \\
\hline 0.1 & 0.14 \\
\hline 0.3 & 0.42 \\
\hline 0.7 & 0.99 \\
\hline 1 & 1.41 \\
\hline 3 & 4.22 \\
\hline 5 & 7.04 \\
\hline 7 & 9.86 \\
\hline 10 & 14.08 \\
\hline 15 & 21.12 \\
\hline 20 & 28.16 \\
\hline 25 & 35.2 \\
\hline
\end{tabular}

Table 1. Computational spatial nodes.

\subsection{Neutron flux error}

The percent relative error for the neutron flux for the 1977 and 2001 GCR solar minimum and maximum environments at various shield thicknesses are shown in figure 3 . The figure indicates that for both extreme environments error below $10 \mathrm{MeV}$ is on the order of 50 percent or more with escalating error at lower energies and greater depths. Nearly a factor of two (100 percent) error occurs at the biologically important energy of $1 \mathrm{MeV}$ beyond $25 \mathrm{~g} / \mathrm{cm}^{2}$ of aluminum equivalent PE. At this energy, the proton range in tissue (water) is approximately equal to the skin thickness $\left(0.01 \mathrm{~g} / \mathrm{cm}^{2}\right)$. Finally, the figure indicates that the flux ratios during the 2001 solar maximum are qualitatively similar to those of 1977 solar minimum. 


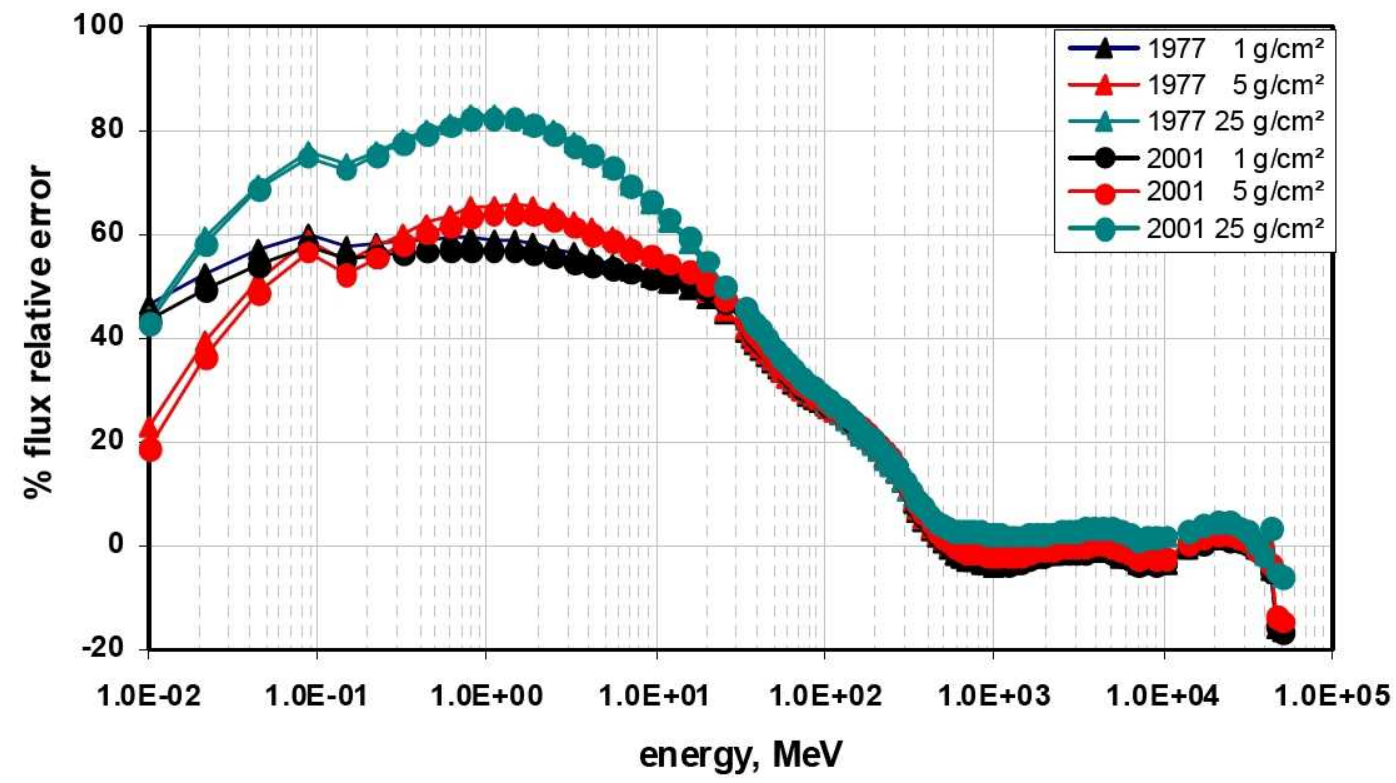

Figure 3. Percent relative error for neutron flux for the 1977 and 2001 GCR environments (PE vs. aluminum equivalent PE).

\subsection{Light ion flux error}

The corresponding flux percent error for the combined light ions (proton, deuteron, triton, helion and helium) is shown in figure 4 . In the figure, the error due to the aluminum equivalent approximation is on the order of 40 percent at $10 \mathrm{MeV}$ and decline to smaller values at higher energies where the penetrating primary ions dominate the spectrum. Below $10 \mathrm{MeV}$, the error rises to over 50 percent at $1 \mathrm{MeV}$ with a continued rise to higher percentages at the lowest energies.

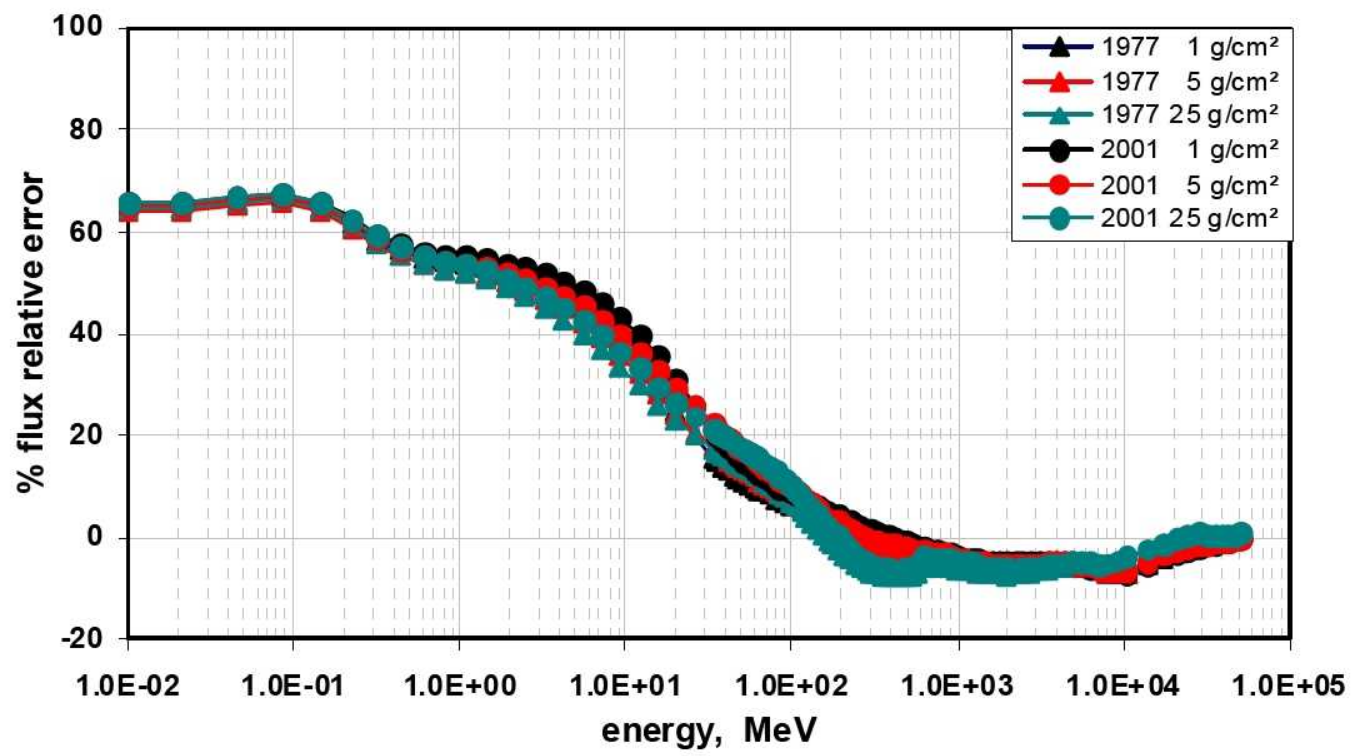

Figure 4. Percent relative error for the combined light ion (proton, deuteron, triton, helion and helium) flux for the 1977 and 2001 GCR environments (PE vs. aluminum equivalent PE). 


\subsection{Light-medium ion flux error}

Figure 5 shows the combined charges 3 through 10 ion group percent error. The figure indicates that the error is on the order of 50 percent at the lowest energies and declines to about 20 percent at $10 \mathrm{MeV}$. The figure also indicates that the charge group has a gradual error build up at higher depths and energies. The increase in error at higher depths and energies is due to the collisional energy losses of the heavier elements in the charge group and is expected to increase for even heavier elements.

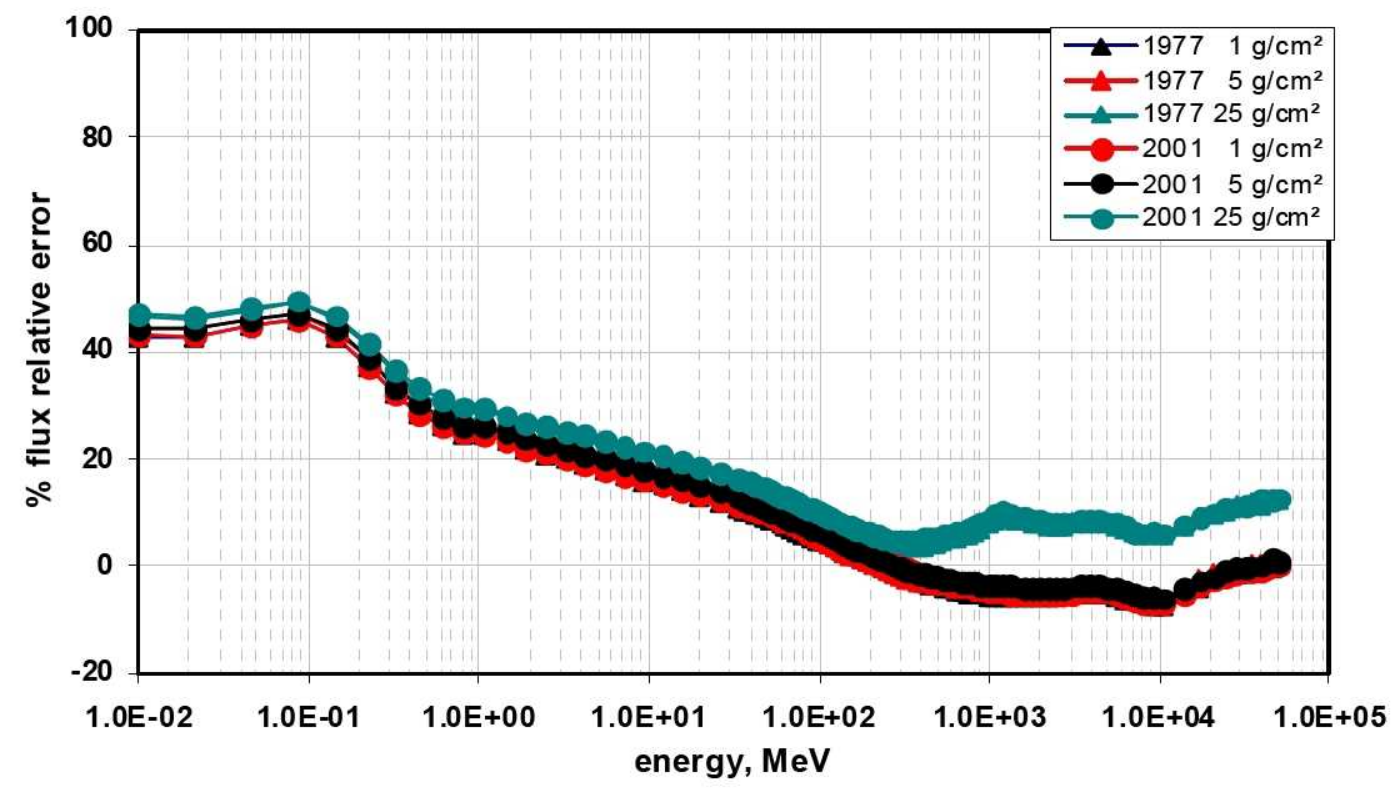

Figure 5. Percent relative error for the combined charges 3 through 10 ion group flux for the 1977 and 2001 GCR environments (PE vs. aluminum equivalent PE).

\subsection{Medium and heavy ion flux error}

The relative error for the remaining ion groups, the combined 11 through 20 charge group and the combined 21 through 28 charge group, are shown in figures 6 and 7, respectively. Their qualitative behavior is similar to the charge 3 through 10 group with a noticeable rise in the percent error at higher depths and energies. Figure 6 indicates that at a depth of $25 \mathrm{~g} / \mathrm{cm}^{2}$, the percent error across the entire GCR energy range exceeds 30 percent, while in figure 7 , at the same depth, due to the presence of the even heavier GCR constituents and higher collisional losses, the error remains above 50 percent.

The flux relative error comparison in the previous sections indicates that, with the exception of heavier ion groups $(11 \leq Z \leq 20$ and $21 \leq Z \leq 28)$ where collisional losses are large, the GCR ions with energies above $1 \mathrm{GeV}$ easily penetrate the maximum depth of the target material in this study $\left(25 \mathrm{~g} / \mathrm{cm}^{2}\right)$. This was shown by the near zero relative error above $1 \mathrm{GeV}$ for lighter charge groups. However, for a large habitable structure (e.g. ISS) where in some directions the areal thickness are well above $25 \mathrm{~g} / \mathrm{cm}^{2}$, this small relative error can become considerably larger. 


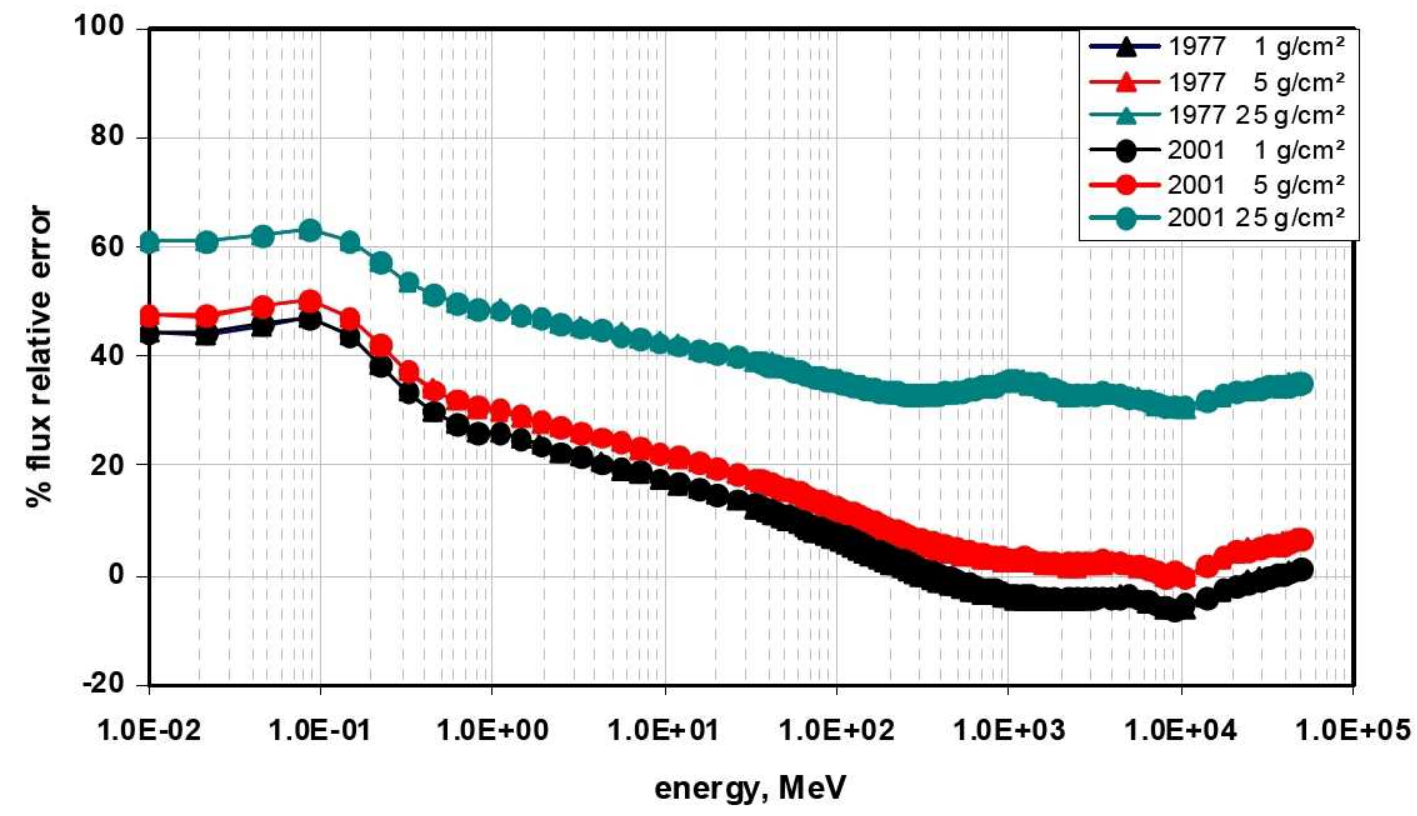

Figure 6. Percent relative error for the combined charges 11 through 20 ion group flux for the 1977 and 2001 GCR environments (PE vs. aluminum equivalent PE).

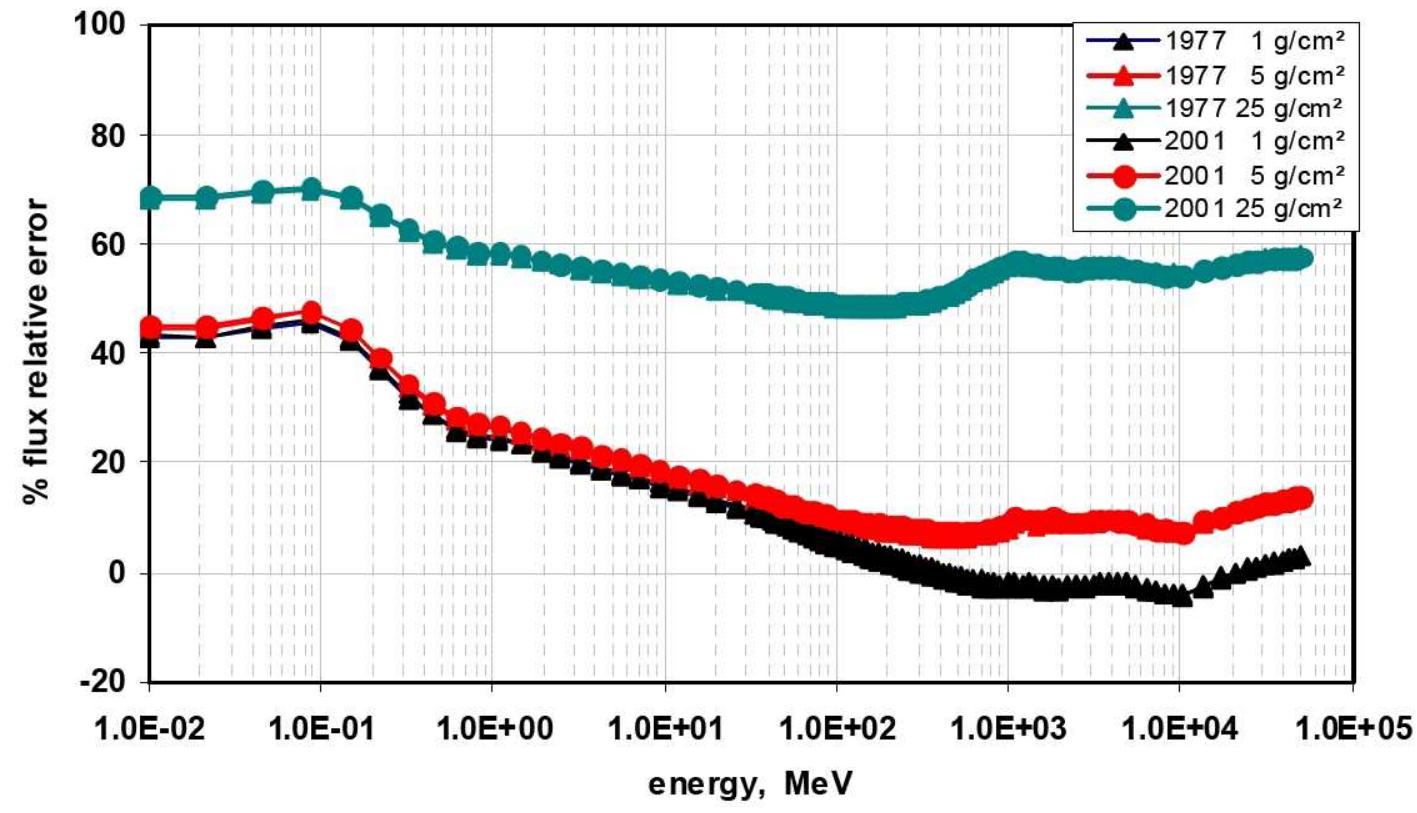

Figure 7. Percent relative error for the combined charges 21 through 28 ion group flux for the 1977 and 2001 GCR environments (PE vs. aluminum equivalent PE). 


\subsection{Dose error}

For dose error analysis, the absorbed dose (D) due to the energy deposition at a given location depth $\mathrm{x}$ of the target material by all GCR ions, is calculated according to

$$
\mathrm{D}(\mathrm{x})=\sum_{\mathrm{j}} \int \varphi_{\mathrm{j}}(\mathrm{x}, \mathrm{E}) \mathrm{S}_{\mathrm{j}}(\mathrm{E}) \mathrm{dE}
$$

where $\varphi_{j}(x, E)$ is the flux type $j$ ion at depth $x$ with kinetic energy $E$, and $S_{j}(E)$ is the stopping power of type $\mathrm{j}$ ion with kinetic energy $\mathrm{E}$.

Applying equations 1 and 2, the percent relative error in absorbed dose using PE and aluminum equivalent PE as targets, for various shield thicknesses, is shown in figure 8 . The figure indicates that using PE and aluminum equivalent PE as targets, the relative error for the 2001 solar maximum is larger than the 1977 solar minimum. This error is not to be confused with the actual absorbed dose values for each epoch where the 1977 solar minimum produces larger absolute dose values than the 2001 solar maximum.

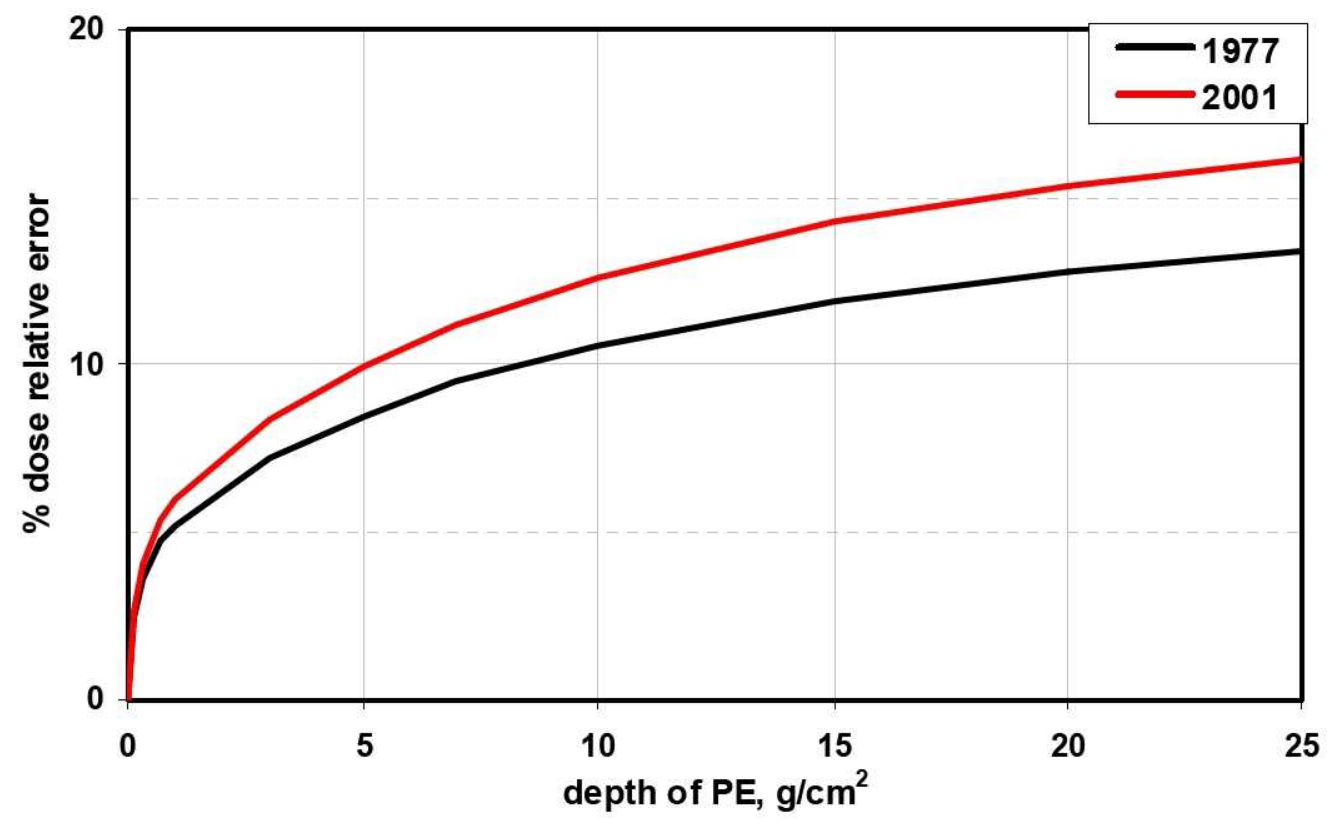

Figure 8. Percent relative error for the absorbed dose for the 1977 and 2001 GCR environments (PE vs. aluminum equivalent $\mathrm{PE}$ ).

Figure 8 indicates that percent relative error due to the approximation, for both GCR extremes integrated across the charge and energy range, is increasing even at the limiting PE depth of $25 \mathrm{~g} / \mathrm{cm}^{2}$ of this study. For a large habitable spacecraft module this error can result in incorrect absorbed dose estimation at a given target point within the module.

It is worth noting that the magnitude of the absorbed dose error is significantly less than the flux error of previous sections. This is due to the integrated nature of equation 2 where large errors at low energies are compensated by small errors at higher energies. 


\subsection{Multifunctional polymer error}

In previous studies (refs. 15, 16), HZETRN, in conjunction with appropriate environments (ref. 12), was used to explore the response of commercially available, hydrogen rich polymers to ionizing radiation, as a first step toward the long term goal of developing multifunctional composite structural configurations and manufacturing methodologies to reduce spacecraft weight while maintaining structural, damage tolerance and radiation shielding requirements. The best such hydrogen rich multifunctional polymers with acceptable structural properties are aliphatic polymers such as high-density PE fibers, epoxy matrix/adhesive and PE foams. Such polymers will most likely have to be manufactured in the form of sandwich structures where the lightweight and radiation tolerant core is supported by stiff fiberglass/epoxy or carbon/epoxy facesheets to form a structurally efficient membrane.

In this section, we apply the approximation to some of these commercial grade polymers to develop a quantitative understanding of the extent of relative error in the absorbed dose. We will then compare these errors with the PE error of the previous section to draw conclusions about whether the approximation should be used for polymers in general.

Table 2 is an abbreviated list of the important physical and chemical properties of the seven candidate polymers studied in reference 16 . In the table, elemental percentages in red refer to the highest percentile concentration of elements $\mathrm{H}, \mathrm{C}, \mathrm{N}$ and $\mathrm{O}$.

\begin{tabular}{|c|c|c|c|}
\hline Material & Description & $\begin{array}{l}\text { Density } \\
\left(\mathrm{g} / \mathrm{cm}^{3}\right)\end{array}$ & $\begin{array}{c}\text { Chemical } \\
\text { Composition (mass\%) }\end{array}$ \\
\hline Polyethylene & generic PE & 0.94 & \\
\hline Resin 1 & Epoxy resin block & 1.12 & $70.1 \% \mathrm{C} \quad 7.6 \% \mathrm{H} \quad 16.8 \% \mathrm{O} \quad 5.5 \% \mathrm{~N}$ \\
\hline Facesheet 1 & Spectra/epoxy facesheet & 1.04 & $77.3 \% \mathrm{C} \quad 10.7 \% \mathrm{H} \quad 9.0 \% \mathrm{O} \quad 3.0 \% \mathrm{~N}$ \\
\hline Facesheet 2 & Carbon/epoxy composite & 1.44 & $83.5 \% \mathrm{C} \quad 3.6 \% \mathrm{H} \quad 7.10 \% \mathrm{O} \quad 5.8 \% \mathrm{~N}$ \\
\hline Core 1 & PET $^{*}$ foam block & 0.35 & $62.5 \% \mathrm{C} \quad 4.2 \% \mathrm{H} \quad 33.3 \% \mathrm{O}$ \\
\hline Core 2 & PP* foam block & 0.19 & $85.6 \% \mathrm{C} \quad 14.4 \% \mathrm{H}$ \\
\hline \begin{tabular}{|c|} 
Sandwich \\
Composite 1
\end{tabular} & $\begin{array}{c}0.35 \mathrm{~g} / \mathrm{cm}^{3} \mathrm{PET}^{*} / \text { Spectra } \\
\text { facesheet }\end{array}$ & 0.52 & $69.9 \% \mathrm{C} \quad 7.4 \% \mathrm{H} \quad 21.4 \% \mathrm{O} \quad 1.3 \% \mathrm{~N}$ \\
\hline $\begin{array}{c}\text { Sandwich } \\
\text { Composite } 2\end{array}$ & $\begin{array}{c}\text { FR6720 Polyurethane/carbon } \\
\text { facesheet }\end{array}$ & 0.53 & $\begin{array}{c}75.2 \% \mathrm{C} \quad 4.6 \% \mathrm{H} \quad 13.2 \% \mathrm{O} \quad 6.4 \% \mathrm{~N} \\
0.3 \% \mathrm{P}<1 \% \text { Trace elements }\end{array}$ \\
\hline
\end{tabular}

\section{PET $^{*}$ : Polyethylene Terephthalate PP* $^{*}$ : Polypropylene}

Table 2. Properties of the target multifunctional polymers investigated. 
Since the aluminum equivalent approximation is based on the $50 \mathrm{MeV}$ proton range in any material, table 3 provides the $50 \mathrm{MeV}$ proton range in all the materials listed in table 2 . In addition, the range in aluminum is also included as a reference. The ranges in the table were calculated using HZETRN. For PE and aluminum, the ranges were checked versus National Institute of Standards and Technology (NIST) predictions (ref. 17).

\begin{tabular}{|c|c|}
\hline Material & $\begin{array}{c}\mathbf{5 0} \mathbf{M e V} \text { proton range } \\
\left(\mathbf{g} / \mathbf{c m}^{\mathbf{2}}\right)\end{array}$ \\
\hline Polyethylene & $\mathbf{2 . 0 7}$ \\
\hline Aluminum & $\mathbf{2 . 9 3}$ \\
\hline Resin 1 & 2.25 \\
\hline Facesheet 1 & 2.16 \\
\hline Facesheet 2 & 2.37 \\
\hline Core 1 & 2.37 \\
\hline Core 2 & 2.07 \\
\hline Sandwich Composite 1 & 2.26 \\
\hline Sandwich Composite 2 & 2.35 \\
\hline
\end{tabular}

Table 3. $50 \mathrm{MeV}$ proton range for the target multifunctional polymers investigated.

With properties of these multifunctional polymers defined, we now calculate the percent relative error in absorbed dose for the 1977 and 2001 GCR spectra. Figure 9 displays percent relative error for the absorbed dose. The largest errors for both epochs are due to PE and Core 2 polymers which have very similar properties. Note that the percent absorbed dose relative error of the 2001 solar maximum is somewhat larger than the 1977 solar minimum. As discussed previously, this error is not to be confused with the actual absorbed dose values for each epoch where the 1977 solar minimum produces larger absolute dose values than the 2001 solar maximum.

Figure 9, which in essence is a composite representation of aluminum equivalent approximation to most polymers, indicates that the application of this approximation to polymers results in incorrect dose calculation and should be avoided. Note that in the figure, even at a depth of $25 \mathrm{~g} / \mathrm{cm}^{2}$, which is most likely well below the 50 percentile average thickness of ISS for the 2008 configuration of $1 \mathrm{~J}$ (ref. 18), the error is about 16 percent and increasing. This error level points to the problem that use of the equivalent approximation can result in incorrect dose estimation at a given target point. 

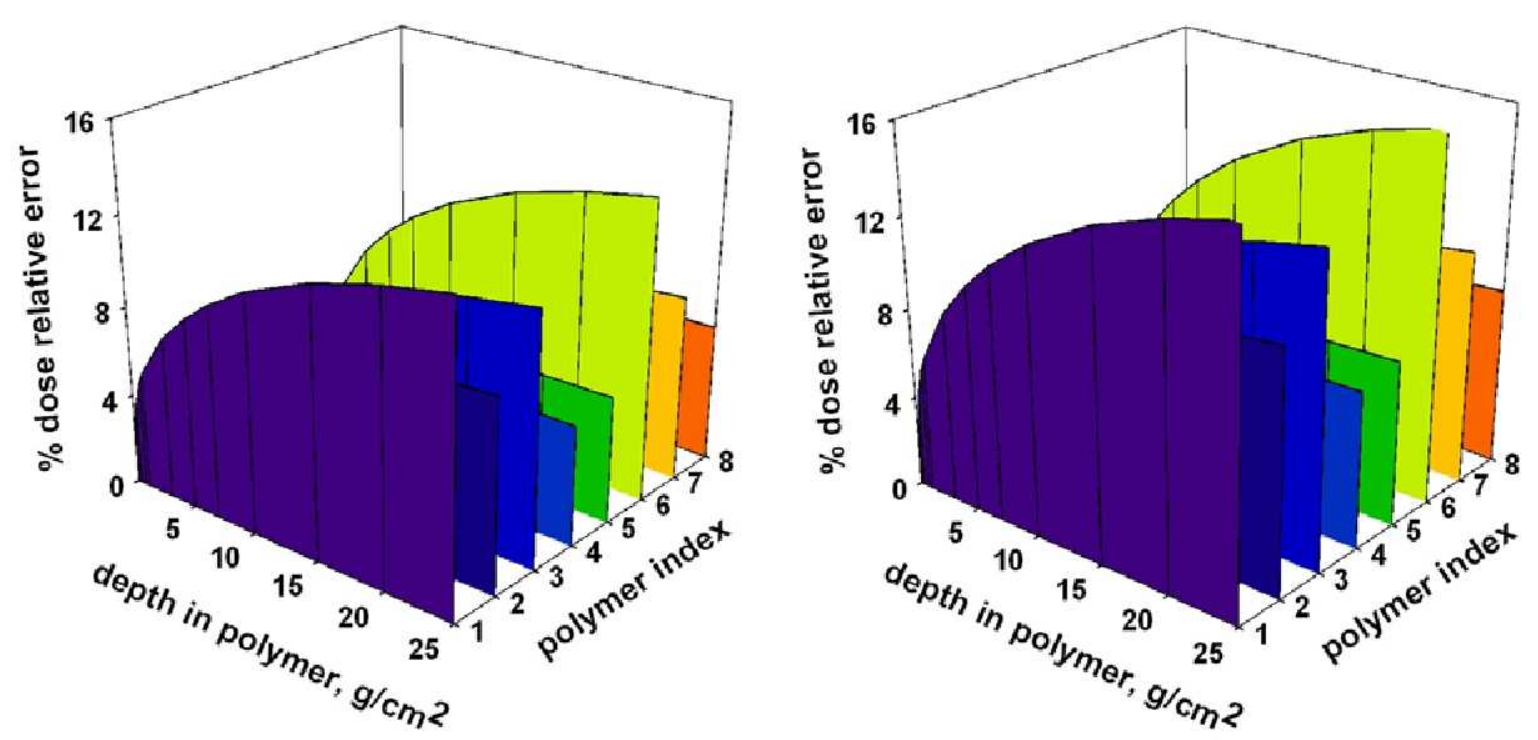

\begin{tabular}{|c|l|c|}
\hline 1 & - & PE \\
\hline 2 & - & Resin 1 \\
\hline 3 & - & Facesheet 1 \\
\hline 4 & - & facesheet 2 \\
\hline 5 & - & Core 1 \\
\hline 6 & - & Core 2 \\
\hline 7 & - & Sandwich Composite 1 \\
\hline 8 & - & Sandwich Composite 2 \\
\hline
\end{tabular}

Figure 9. Percent relative error for the absorbed dose for the 1977 and 2001 GCR environments (multifunctional polymer vs. aluminum equivalent multifunction polymer).

\section{Conclusion}

This paper elaborated on the historical justifications for the sole emphasis on atomic interactions, and why nuclear collisions were essentially ignored. Also discussed was the fact that from a vehicle design point of view, shield properties, neglecting nuclear reactions, can be scaled from one material to another with a fair degree of accuracy, relative ease, and huge saving on computational time. The relative ease of material scaling combined with the acceptable turn around time for numerical simulation were indeed the impetus behind the equivalent approximation concept for the first thirty years of the space program.

The aluminum equivalent shield approximation was a matter of convenience when dose was the monitored quantity to guard against potential radiation sickness in the early space program. With soon to be established permanent human presence in space (ISS) and potentially a lunar base, and the search for mitigation methodologies to minimize exposure by appropriate choice of shielding materials, applying the equivalent approximation to polymers is no longer justifiable. Under the GCR exposures considered herein, this study showed that for polymer 
based shielding materials, the approximation produced large errors in flux and absorbed dose estimations.

Clearly, with the advent of fast numerical marching techniques such as HZETRN and other deterministic algorithms and the rapid maturation of high performance computers, the use of this approximation is unjustifiable for polymers.

\section{References}

1. NAS/NRC, Radiobiological Factors in Manned Space Flight, W. H. Langham ed., National Academy Press, 1967.

2. J. W. Haffner, Radiation and Shielding in Space, Academic Press, New York, 1967.

3. M. O. Burrell, The Calculation of Proton Penetration and Dose Rates, NASA TM X-53063, 1964.

4. NAS/NRC, Radiation Protection Guides and Constraints for Space Mission and VehicleDesign Involving Nuclear Systems, W. H. Langham and D. Grahn, eds., National Academy Press, 1970.

5. J. W. Wilson and G. S. Khandelwal, Proton Tissue Dose Approximation in Arbitrary Convex Geometry, Nucl. Tech. 1 - 23, 298-305, 1974.

6. J. W. Wilson and G. S. Khandelwal, Proton-Tissue Dose Buildup Factors, Health Physics $31,115-118,1976$.

7. J. Baarli and K. Goebel, Properties of High Energy Beams from a $600 \mathrm{MeV}$ Synchrocyclotron, Proc. XI Intern. Congress of Radiology, Rome, Sept. 1965, 2, 1837, Excerpta Medica Foundation, New York, 1967.

8. J. W. Wilson, L. W. Townsend, W. Schimmerling, G. S. Khandelwal, F. Khan, J. E. Nealy, F. A. Cucinotta, L. C. Simonsen, J. L. Shinn and J. W. Norbury, Transport Methods and Interactions for Space Radiations, NASA RP-1257, 1991.

9. S. B. Curtis, J. E. Nealy and J. W. Wilson, Risk Cross Sections and their Application to Risk Estimation in the Galactic Cosmic Ray Environment, Radiat. Res. 141, 57-65, 1995.

10. W. S. Schimmerling, J. W. Wilson, F. A. Cucinotta and M. H. Y. Kim, Requirements for Simulating Space Radiation with Particle Accelerators. Chapter 1 of Risk Evaluation of Cosmic Ray Exposure in Long Term Manned Space Mission, K. Fujitaka, H. Majima, K. Ando, H. Yasuda and M. Suzuki, eds., Kodansha Scientific Ltd., Tokyo, 1999.

11. T. W. Armstrong, B. L. Colborn and S. J. Ringler, Radiation Dose Estimation to the Crew Inside the International Space Station Lab, Hab, Node 1, Node 2, and Airlock modules, SAIC-TN-9601, Jan. 1996.

12. F. F. Badavi, K. J. West, J. E. Nealy, J. W. Wilson, B. L. Abrahms and N. J. Luetke, A Dynamic/Anisotropic Low Earth Orbit (LEO) Ionizing Radiation Model, NASA-TP-2006214533, 2006.

13. P. M. O’Neill, Badhwar-O’Neill Galactic Cosmic Ray Model Update Based on Advanced Composition Explorer (ACE) Energy Spectra from 1997 to Present, Adv. Space Res. 37, 1727-1733, 2006.

14. J. W. Wilson, R. K. Tripathi, F. F. Badavi and F. A. Cucinotta, Standardized Radiation Shield Design Method: 2005 HZETRN, ICES 2006, SAE, 2006-01-2109, July 2006. 
15. D. O. Adams, N. J. Webb, C. B. Yarger, A. Hunter and K. D. Oborn, Multi-Functional Sandwich Composites for Spacecraft Applications: An Initial Assessment, NASA-CR-2007$214880,2007$.

16. F. F. Badavi, C. R. Stewart-Sloan, D. O. Adams and J. W. Wilson, Radiation Protection Effectiveness of Polymeric Based Shielding Materials at Low Earth Orbit, SAMPE paper 2008-L002, May 2008.

17. Stopping-Power and Range Tables for Electrons, Protons, and Helium Ions, http://physics.nist.gov/PhysRefData/Star/Text/contents.html, August 2005.

18. ISS Assembly Mission 1J (STS-124), http://www.nasa.gov/mission pages/station/structure/iss assembly 1j.html, May 31, 2008. 


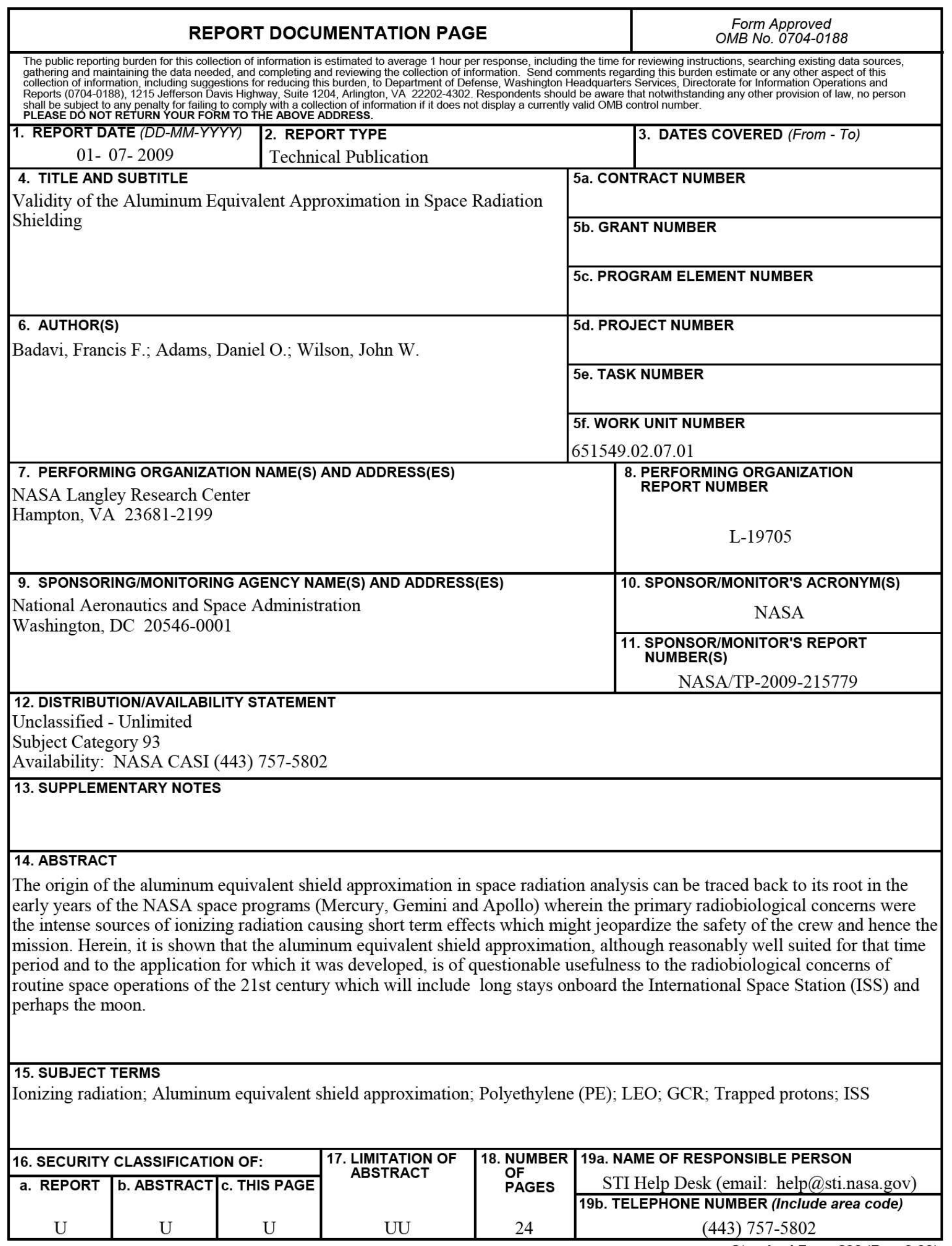

